\title{
THE ONE-VOICE MODEL OF A \\ CORPORATE SPORTS ACCOUNT: KNOWLEDGE \\ MANAGEMENT AT WORK \\ Tiffany Norris UT Dallas
}




\section{Research Research Interest

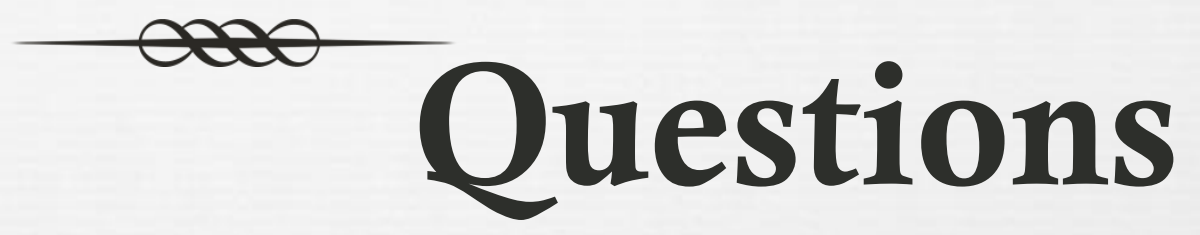

$\infty$ Changing role of journalists

(s) Implications of multiple operators working as a team to present a common face under the banner of one account

œ Social network analysis

@ ESPN's SportsCenter Twitter account
Q T) To what extent does social network theory explain the operations of the social media team responsible for a selection of ESPN's Twitter accounts?

Co a) To what extent does this team exhibit network properties?

(a) b) How are these network properties influenced by a multioperator organizational design where multiple people are responsible for one Twitter account? 


\section{Foundational Concepts}

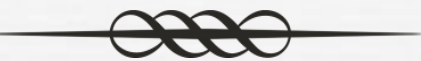

Journalist as Information Provider

Q8 Journalism, like information science, is a "meta-field," one that "cuts across, or is orthogonal to, the conventional academic disciplines" (Bates, 1999, p. 1044).

$\infty$ Larsson (2013) noted that journalists have traditionally been viewed as gatekeepers, but that role has been changing with the evolution and expansion of technology.

@ Democratization of information

\section{Social Network Theory}

(2) "The basics of social networks are straightforward: 'actors' maintain 'relations' with others which form the 'tie' between them. The collective set of actors and ties forms the 'network' of connections among all members of the particular social set. Analyses and visualizations of networks follow graph theory with the actors as the nodes and relations as lines between nodes" (Haythornthwaite, 2010, p. 4838). 


\section{Background Information}

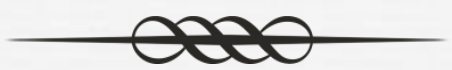

\section{Twitter}

(a) Microblogging site with 313 million monthly active users

Q Influential force in media in general and sports journalism in particular (Hambrick et al., 2010; Shockley, 2010; Spezia, 2011)

\section{ESPN}

(s) Eight member Social Production Group

$\infty$ Curate, create, collaborate

\& More than 32 million followers 


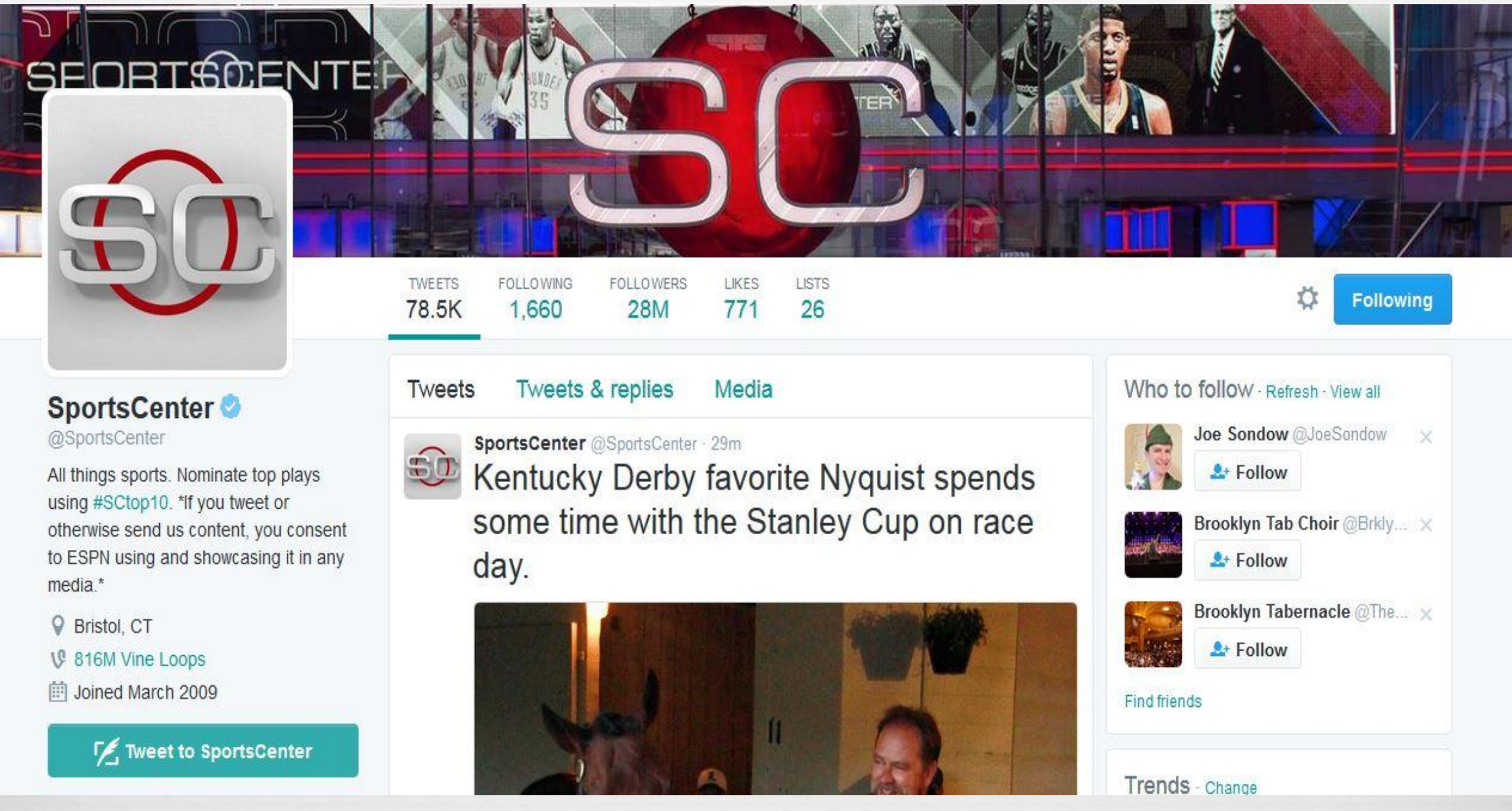

\section{http://twitter.com/SportsCenter}




\section{Methodology}

000

$\infty$ Research design

$\leftrightarrow$ Descriptive, exploratory perspective

$\infty$ Participants

\& Eight member Social Production Group at ESPN

@ Data collection and analysis

c) Surveys (Cross \& Parker, 2004; Wasserman \& Faust, 1994)

$\infty$ Interviews and observation (Cross \& Parker, 2004) 


\section{Data \\ Collection:}

\section{Written Surveys}

-

* Four statements

*ive levels of ranking

* Additional space for comments

- Goal of identifying network patterns

* Based on Cross and Parker (2004)

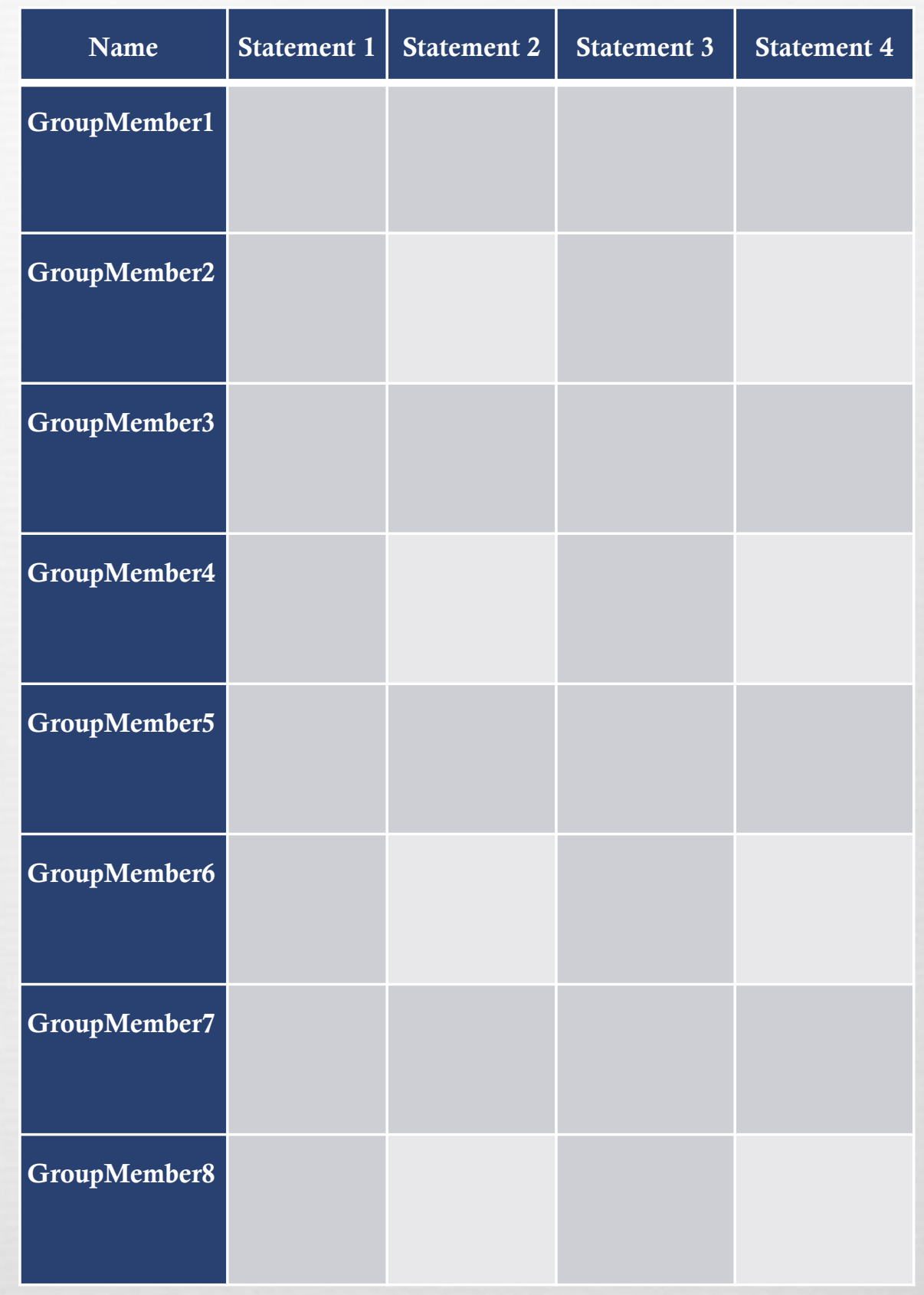




\section{Data Collection: On-site}

\section{Interviews \& Observations}

$œ$ Travel over two days

$\infty$ Up to 60 minutes with each team member

Q8 Observe formal and informal meetings

$\infty$ Digitally recorded and transcribed

(2) Semi-structured interviews related to group, communication, and Twitter

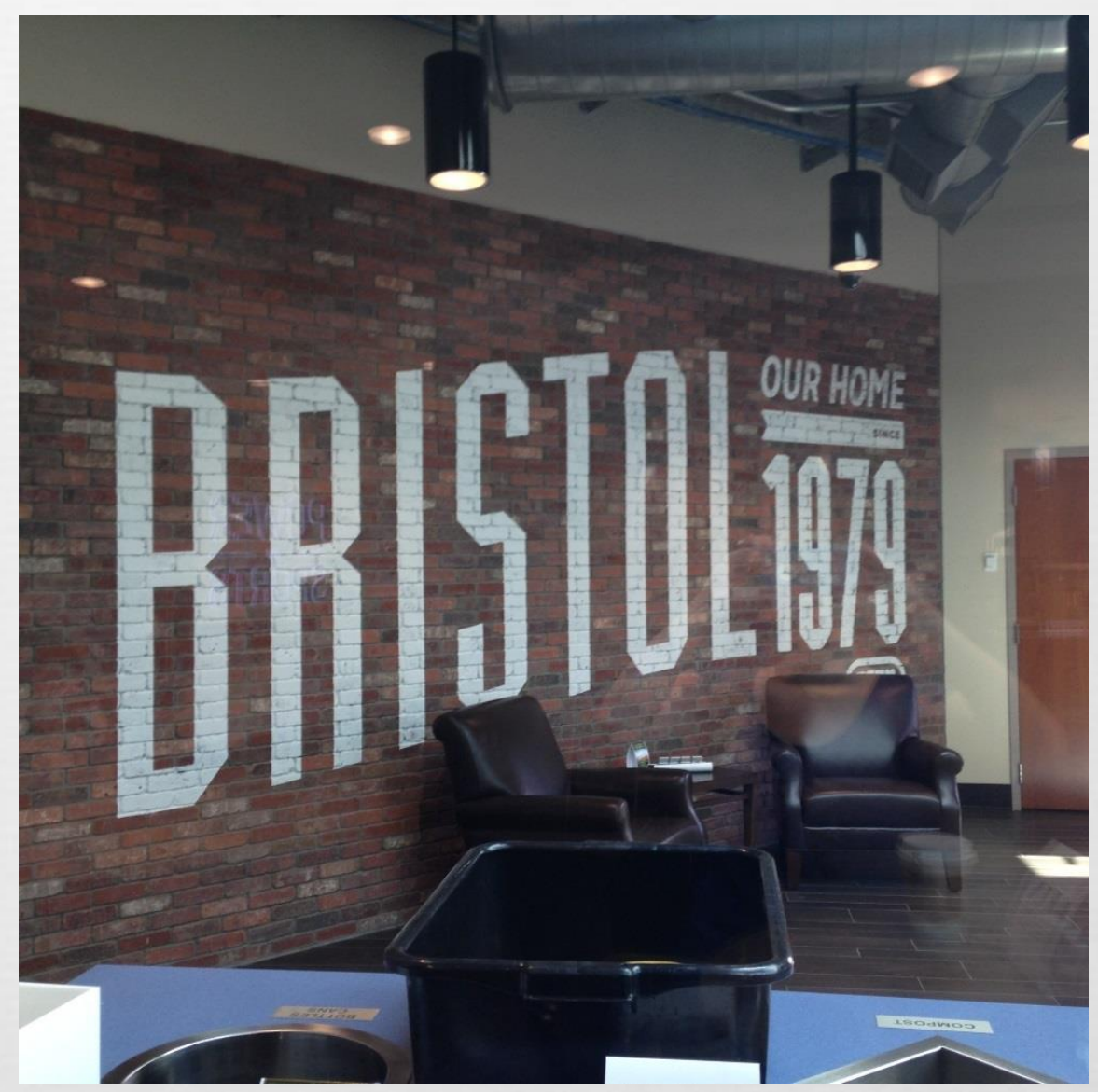




\section{Results: Density}

\begin{tabular}{|l|l|l|}
\hline & $\begin{array}{l}\text { Density, Dichotomized where 1, } \\
2,3=1 ; 4,5=0\end{array}$ & $\begin{array}{l}\text { Density, Dichotomized where 1, 2 = } \\
1 ; 3,4,5=0\end{array}$ \\
\hline $\begin{array}{l}\text { Statement 1: I typically turn to } \\
\text { this person for information about } \\
\text { work-related topics. }\end{array}$ & 0.892857 & 0.660714 \\
\hline $\begin{array}{l}\text { Statement 2: I typically provide } \\
\text { information to this person on } \\
\text { work-related topics. }\end{array}$ & 0.910714 & 0.785714 \\
\hline $\begin{array}{l}\text { Statement 3: I typically turn to } \\
\text { this person for help in thinking } \\
\text { through a challenging problem at } \\
\text { work. }\end{array}$ & 0.732143 & 0.535714 \\
\hline $\begin{array}{l}\text { Statement 4: I typically } \\
\text { collaborate or discuss new or } \\
\text { innovative work-related ideas } \\
\text { with this person. }\end{array}$ & 0.857143 & 0.607143 \\
\hline Statements One and Two & 0.768 & 0.786 \\
\hline
\end{tabular}




\section{Results: Sociograms}

020

Statements One and Two, dichotomized and with tie strength illustrated

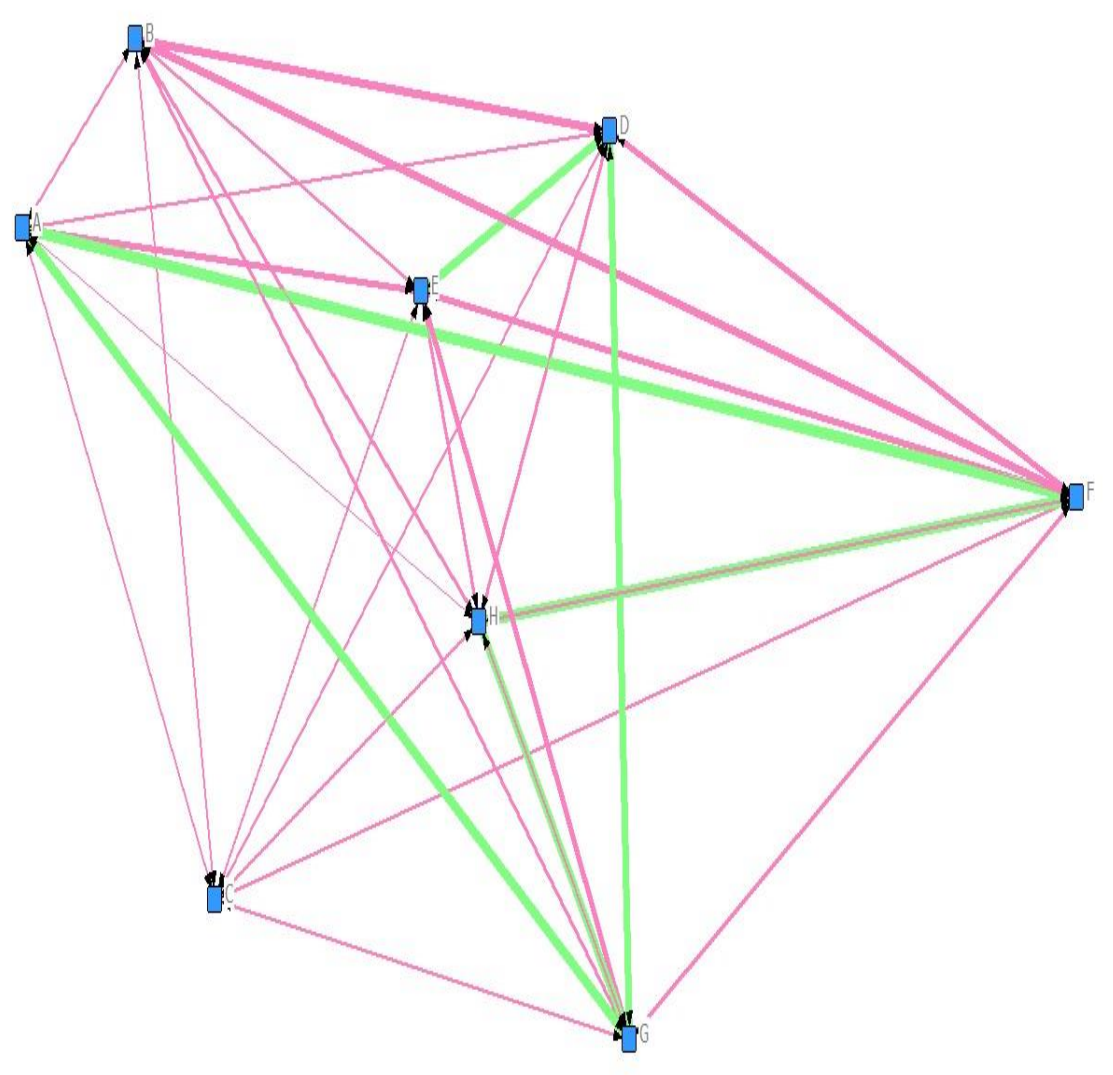

Statement Three, dichotomized, with reciprocated ties in blue

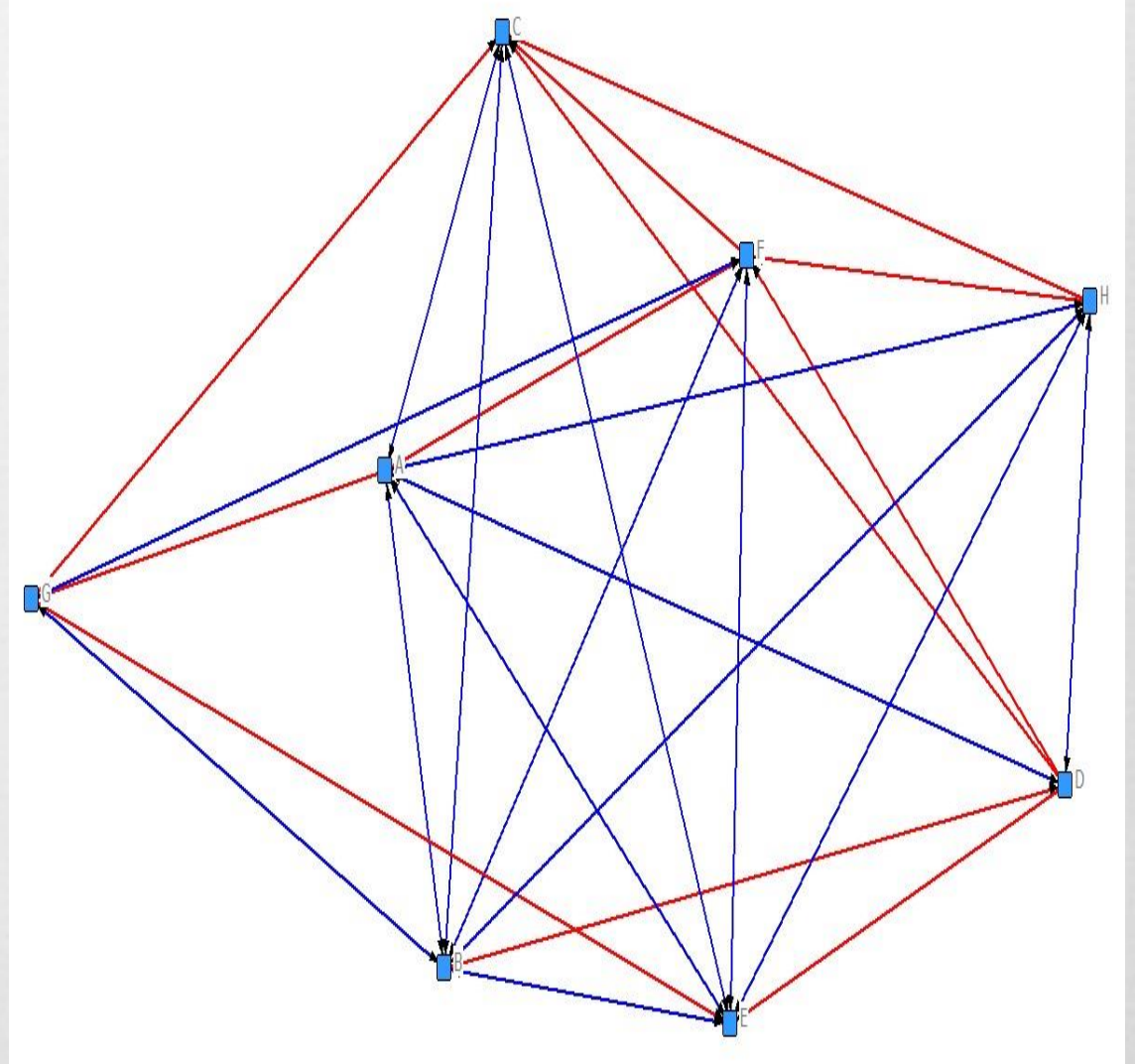




\section{The One Voice Model}

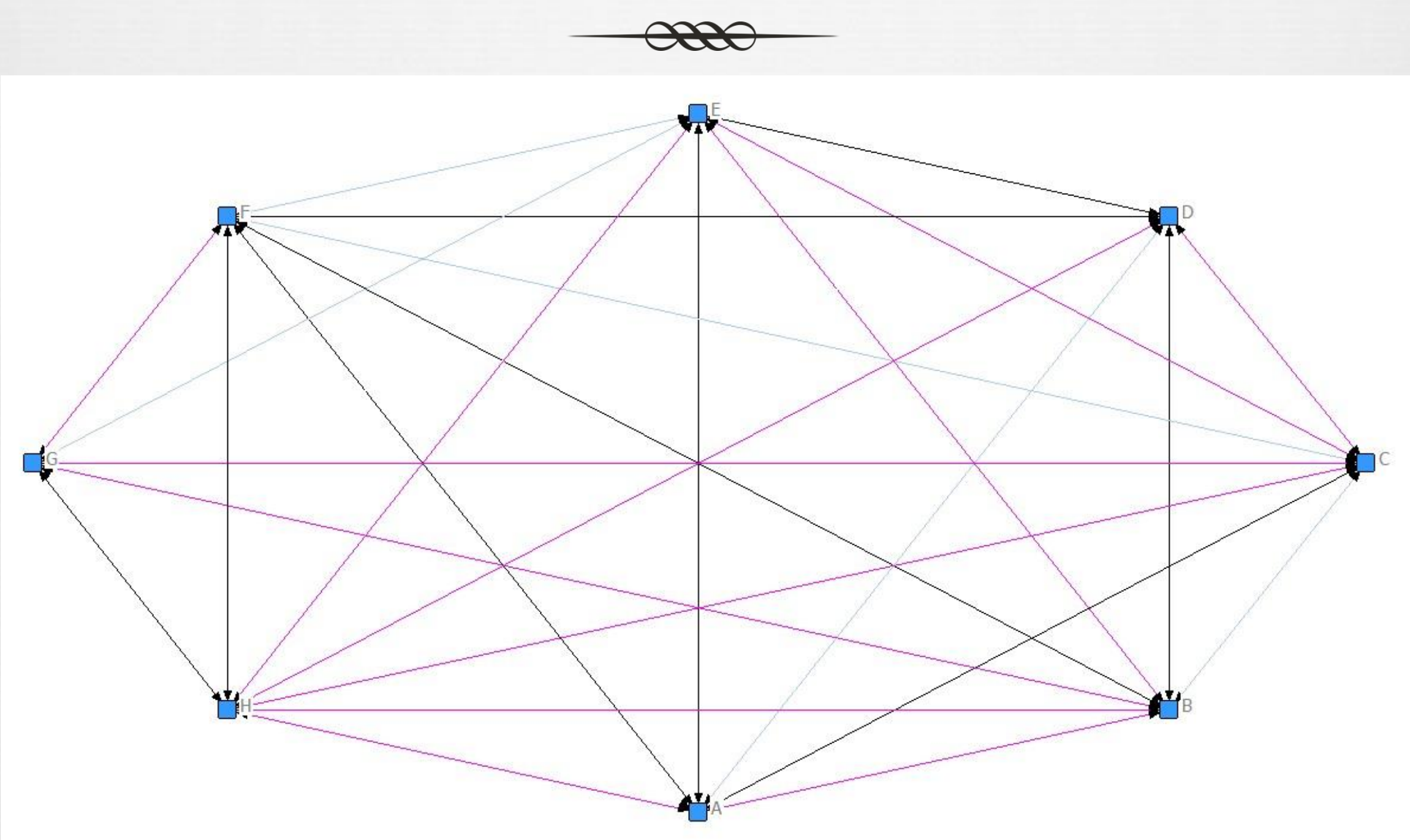


Results: On-site Interviews

\section{and Observations}

000

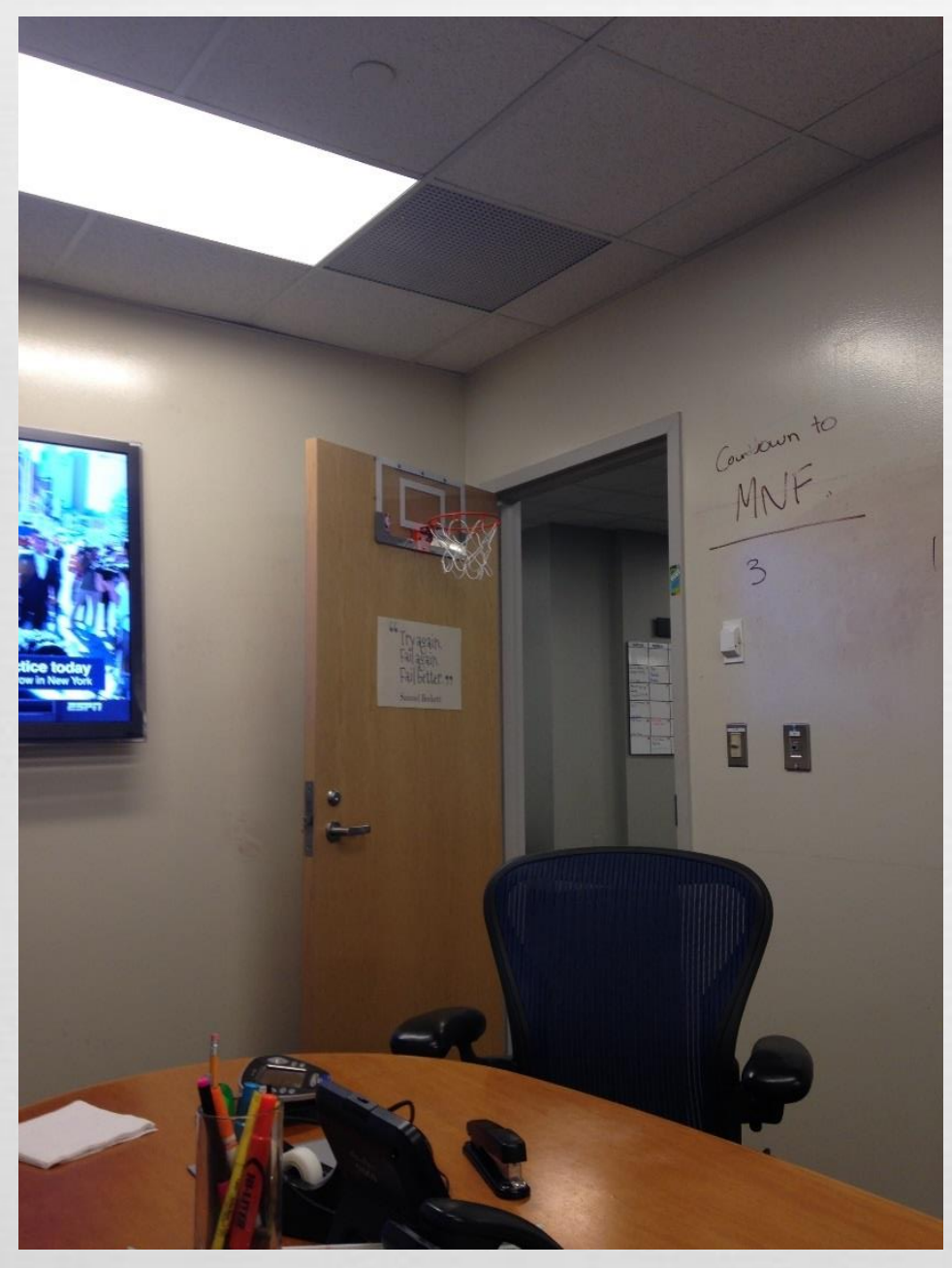

@ Demographics

œ Social network measurements

↔ Interview responses

\& Emergent themes 


\section{Participant Quote}

000

"So in terms of collaboration, conversations are like, 'Hey did you see this story? Would you want to click on it? What do you think about sharing this? Is it cool?' kind of stuff like that. And then we kind of think of a way to sell it to the fan and be like, 'Would you click on this if this is what it said?' And we kind of proofread each other's words, that kind of thing. That's on a daily basis." 


\section{Conclusion}

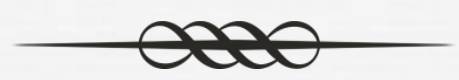

\& Future Research

Directions

\& Theoretical

Implications

\& Practical

Implications

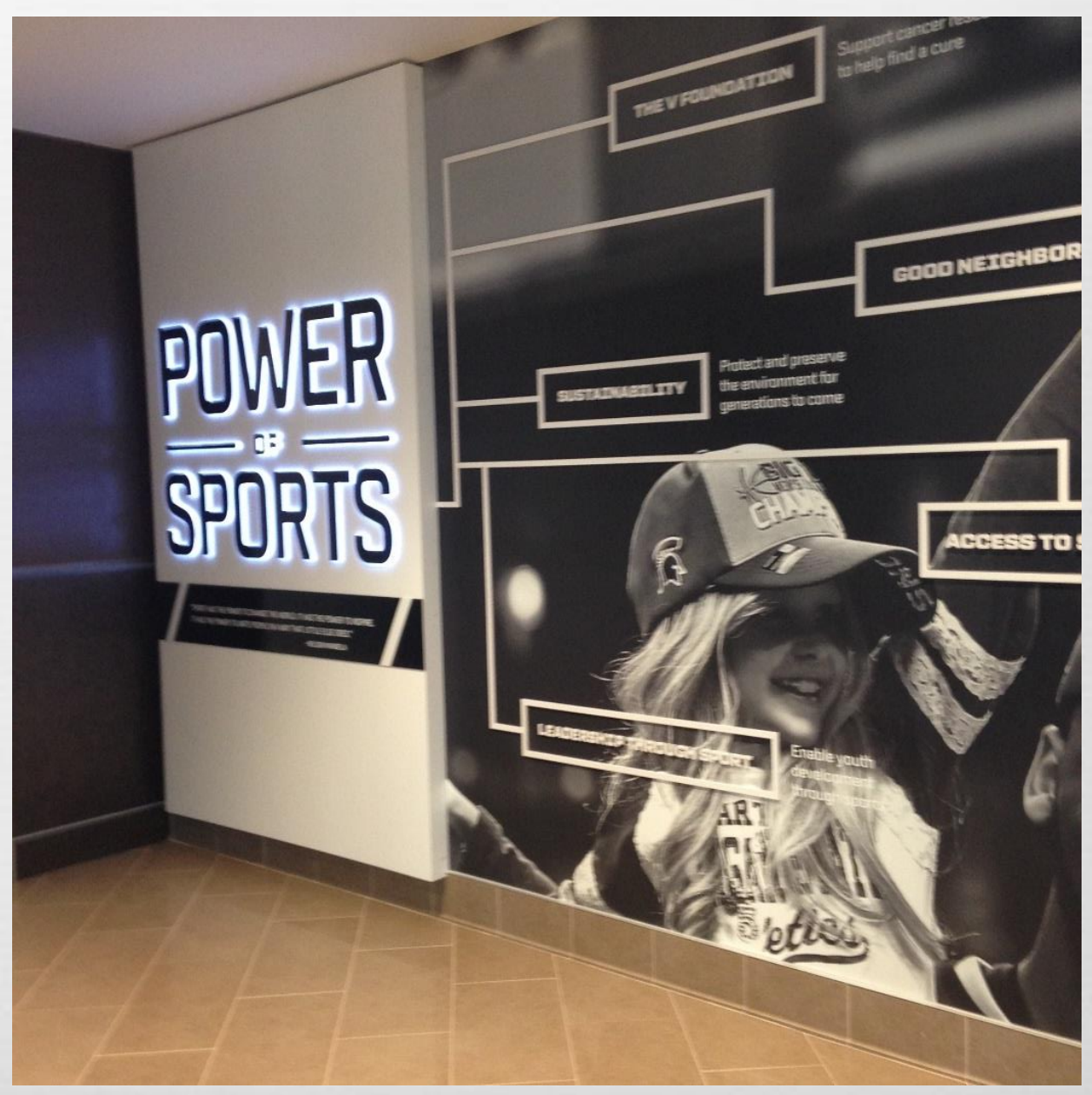




\section{Contact}

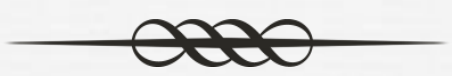

œ Tiffany Norris

œriffanydavisnorris@gmail.com œ2@tiffanydnorris 